\title{
Metaphyseal Dysplasia Without Hypotrichosis Caused by RNA Component of Mitochondrial RNA-Processing Endoribonuclease (RMRP) Gene Variants: The First Case in Korea
}

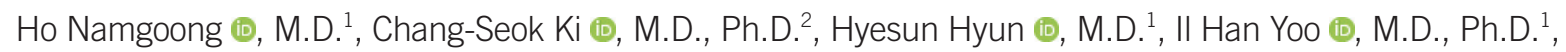

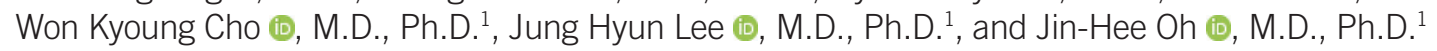 \\ ${ }^{1}$ Department of Pediatrics, College of Medicine, St. Vincent's Hospital, The Catholic University of Korea, Seoul, Korea; ${ }^{2} \mathrm{GC}$ Genome, Yongin, Korea
}

\section{Dear Editor,}

Metaphyseal dysplasia without hypotrichosis (MDWH, OMIM \#250460), a rare phenotype of cartilage-hair hypoplasia (CHH, OMIM \#250250) - anauxetic dysplasia (AD, OMIM \#607095) spectrum disorders, is described as an isolated skeletal dysplasia with no extra skeletal manifestations including hypoplastic hair and defective immunity [1]. Pathogenic variants in RNA component of the mitochondrial RNA-processing endoribonuclease (RMRP) gene cause $\mathrm{CHH}-\mathrm{AD}$ spectrum disorders with autosomal recessive inheritance [2]. We report the first case in Korea of a girl with compound heterozygous RMRP variants, $\mathrm{n} .81 \mathrm{G}>\mathrm{A}$ and $\mathrm{n} .100 \mathrm{C}>\mathrm{T}$, that were diagnosed as MDWH. The Catholic University of Korea St. Vincent's Hospital Institutional Review Board, Seoul, Korea, approved this study (number: VC20ZASE0064).

A girl aged five years and 10 months was referred to the pediatric endocrine clinic at St. Vincent Hospital for short stature. She was the only child of non-consanguineous parents, born at 40 weeks and one day of gestation by spontaneous vaginal delivery, with a birth weight of $2.85 \mathrm{~kg}$ (10th-25th percentile), height of $45 \mathrm{~cm}$ (3th-5th percentile), and normal head circumference. The mid-parental height (maternal height, $166 \mathrm{~cm}$; paternal height, $180 \mathrm{~cm}$ ) was $166.5 \mathrm{~cm}$. Her medical history did not reveal any immunodeficiency warning signs, and she had normal psychomotor development. On physical examination, her weight, measured using a CAS scale (CAS, Seoul, Korea), was $15.9 \mathrm{~kg}$ (-2.1 standard deviation score [SDS]) and her height, measured using a Harpenden Stadiometer (Holtain Ltd., Crymych, UK), was $96.4 \mathrm{~cm}$ (-4.2 SDS). The upper:lower segment ratio (1.3:1) was higher than the normal range for her age (Fig. 1).

The patient's radiographic features revealed subtle cupping and widening at the metaphysis of both metacarpal bones, phalanges, and ulnae, as well as an expanded and irregular costochondral junction in her chest. The chest X-ray revealed a normal thymus. The peripheral blood examination results were as follows: leukocyte count, $5.79 \times 10^{9} / \mathrm{L}$ (neutrophils $49.8 \%$, lymphocytes $39.9 \%$ ); hemoglobin, $135 \mathrm{~g} / \mathrm{L}$ (mean corpuscular volume [MCV] $85.4 \mathrm{fL}$ ); platelet count, $307 \times 10^{9} / \mathrm{L}$; and erythrocyte sedimentation rate, $7 \mathrm{~mm} / \mathrm{h}$ (normal range $0-20 \mathrm{~mm} / \mathrm{hr}$ ). The patient's karyotype was $46, \mathrm{XX}$. The serum levels of calcium
Received: July 27, 2020

Revision received: August 24, 2020

Accepted: November 11, 2020

Corresponding author: Won Kyoung Cho, M.D., Ph.D.

Department of Pediatrics, College of Medicine, St. Vincent's Hospital, The Catholic University of Korea, 93 Jungbu-daero, Paldal-gu, Suwon 16247, Korea

Tel: +82-32-249-8312, Fax: +82-31-257-9311

E-mail: wendy626@catholic.ac.kr 


\section{A}

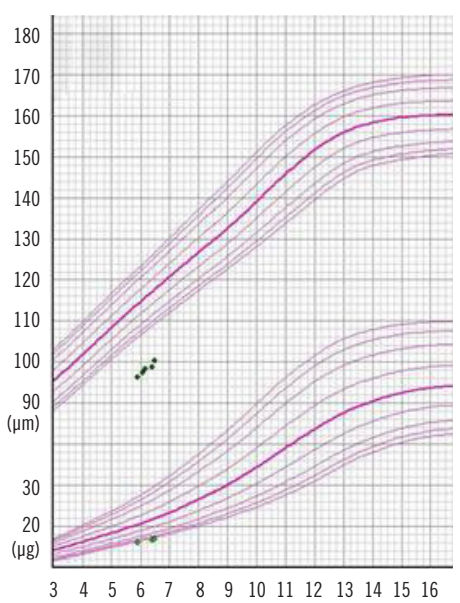

B

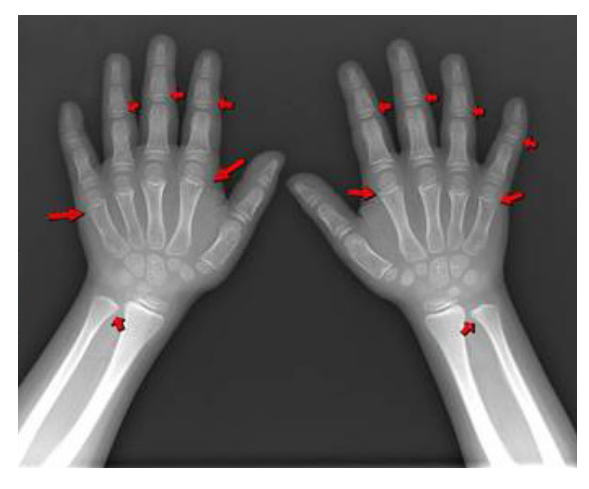

C

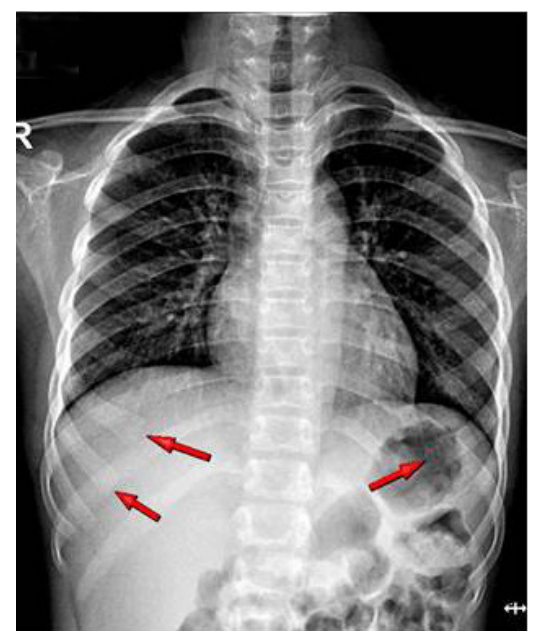

Fig. 1. Physical and radiographic features of the patient. (A) The patient's growth curve shows extremely short stature with poor growth response to growth hormone treatment during the follow-up period. (B) The skeletal radiographic features of this patient revealed subtle cupping and widening at the metaphysis of both metacarpal bones, phalanges, and ulnae, as well as (C) an expanded and irregular costochondral junction in the chest.

[median: $2.42 \mathrm{mmol} / \mathrm{L}$ (range: $2.1-2.59 \mathrm{mmol} / \mathrm{L})$ ], phosphorus [median: $1.48 \mathrm{mmol} / \mathrm{L}$ (range: 0.81-1.45 mmol/L)], and alkaline phosphatase (4.23 $\mu \mathrm{kat} / \mathrm{L}$ (range: $0.5-2 \mu \mathrm{kat} / \mathrm{L}$ ) showed no definite abnormalities. The thyroid and adrenal function tests were normal. The maximum serum growth hormone (GH) level following $\mathrm{GH}$ stimulation in the morning with levodopa $250 \mathrm{mg}$ (Myung In Pharm., Seoul, Korea) and arginine 8 g (GREEN CROSS Well Being, Gyeonggi-do, Korea) was $>10 \mu \mathrm{g} / \mathrm{L}$. The patient was diagnosed as having idiopathic short stature, and $\mathrm{GH}$ treatment $(0.3 \mathrm{mg} / \mathrm{kg} /$ week) was initiated. However, the patient's $\triangle$ height SDS during the six months of GH therapy was 0.2; thus, we ceased $\mathrm{GH}$ treatment owing to poor growth response.

At six years and six months of age, after obtaining written informed consent, genomic DNA was extracted from the patient's peripheral blood leukocytes, and a library was prepared using a custom designed panel (Celemics Inc., Seoul, Korea), which enriches a $616 \mathrm{~kb}$ region spanning 62 short-stature-related genes. Massive parallel sequencing was performed using the IIlumina MiSeqDx platform (Illumina, San Diego, CA, USA). The targeted gene panel sequencing results revealed two variants in RMRP (NR_003051.3:n.81G > A and n.100C > T). Although neither parent consented to be tested for the RMRP variants, the two variants were confirmed as compound heterozygous based on the next generation sequencing results using the Illumina MiSeqDx platform. Therefore, the diagnosis was confirmed nine months after the patient's first visit. $R M R P$ variants $n .81 \mathrm{G}>\mathrm{A}$ (previous nomenclature: $80 \mathrm{G}>\mathrm{A}$ ) and n.100C $>$ T (previous no- menclature: $\mathrm{c} .99 \mathrm{C}>\mathrm{T}$ ) have both been reported in patients with $\mathrm{CHH}[3,4]$ (Fig. 2).

The global incidence of MDWH is unknown; to date, only 20 MDWH patients have been confirmed by RMRP analysis [5-8]; over 90 RMRP variants have been identified in $\mathrm{CHH}-\mathrm{AD}$ spectrum disorders [9]. Although the genetic and molecular background of the genotype-phenotype correlation in patients with $R M R P$ variants is unclear, the position of the pathogenic variants in the transcript and the proposed effect on transcript folding and RNA/protein interaction result in the variable phenotypes observed in $\mathrm{CHH}-\mathrm{AD}$ spectrum disorders [10]. As MDWH patients are deemed mildly affected, clinicians do not always consider potential extraskeletal complications. However, a study reported serious late onset bone marrow failure and cancer risks in MDWH patients [6]. Clinicians should consider mild-phenotype MDWH, even in patients exhibiting only short stature.

\section{ACKNOWLEDGEMENTS}

None.

\section{AUTHOR CONTRIBUTIONS}

Conceptualization: Cho WK; Analysis: Ki CS, Hyun H, Yoo IH, Cho WK, and Namgoong $\mathrm{H}$; and Writing - review and editing: Cho WK, Lee $\mathrm{JH}$, and $\mathrm{Oh} \mathrm{JH}$. 


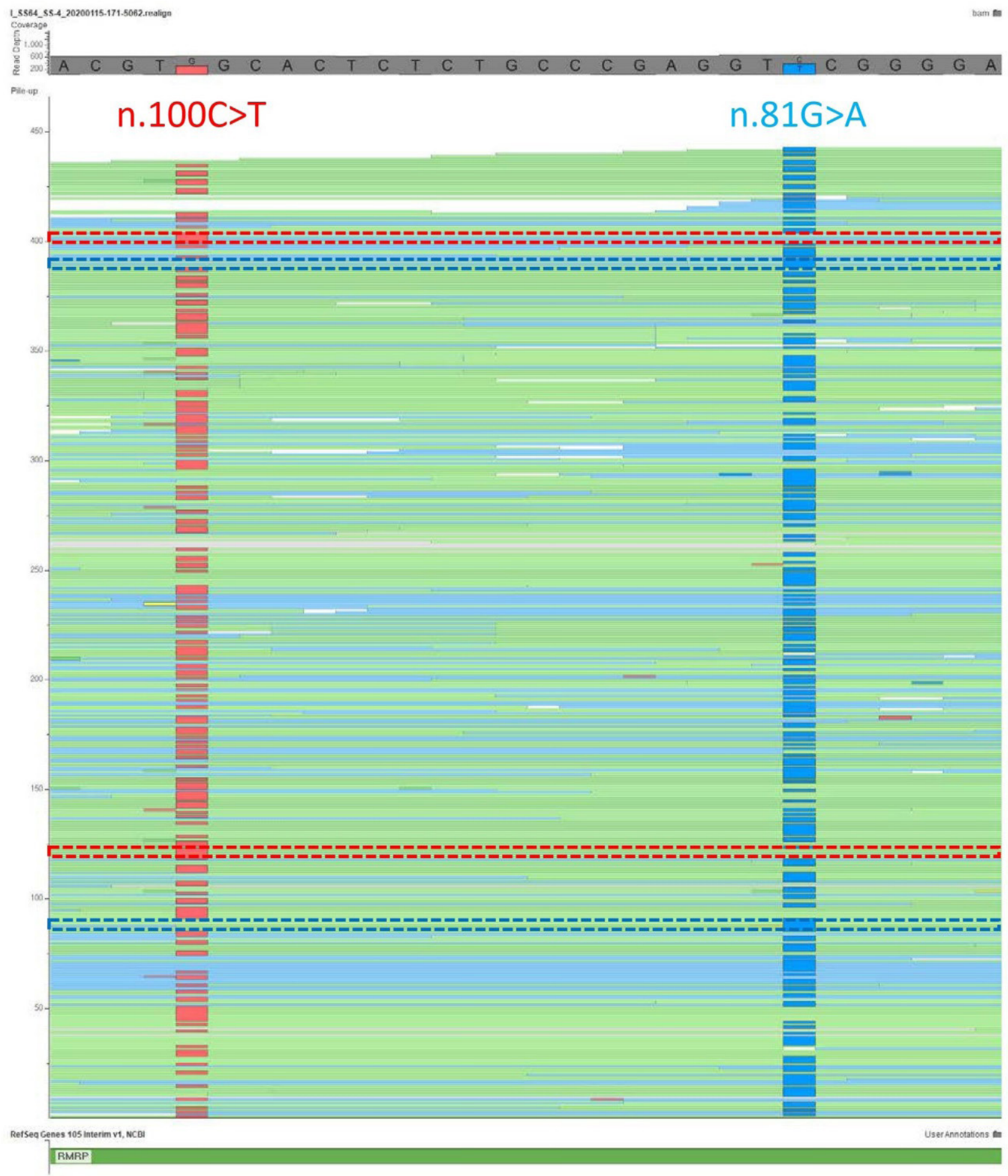

Fig. 2. Integrated genome browser snapshot of the RNA component of mitochondrial RNA-processing endoribonuclease (RMRP) gene variants. The orientation of $R M R P$ is in the reverse direction, so that the $n .100 \mathrm{C}>\mathrm{T}$ variant is on the left and the $\mathrm{n} .81 \mathrm{G}>\mathrm{A}$ variant is on the right. The distance between both variants is $19 \mathrm{bp}$, meaning that many of the variants exist on the same sequence reads, thus confirming the compound heterozygosity of the two variants. The red dotted boxes indicate sequence reads with only the $n .100 \mathrm{C}>\mathrm{T}$ variant, while the blue dotted boxes indicate sequence reads with only the $\mathrm{n} .81 \mathrm{G}>\mathrm{A}$ variant. 


\section{CONFLICTS OF INTEREST}

No potential conflicts of interest relevant to this article were reported.

\section{RESEARCH FUNDING}

None declared.

\section{ORCID}

Ho Namgoong

https://orcid.org/0000-0001-7295-2455

Chang-Seok Ki

https://orcid.org/0000-0001-7679-8731

Hyesun Hyun

https://orcid.org/0000-0001-8525-1471

II Han Yoo

https://orcid.org/0000-0002-7438-6925

Won Kyoung Cho

https://orcid.org/0000-0003-0918-0565

Jung Hyun Lee

https://orcid.org/0000-0002-1849-733X

Jin-Hee Oh

https://orcid.org/0000-0002-2893-0563

\section{REFERENCES}

1. Verloes A, Pierard GE, Le Merrer M, Maroteaux P. Recessive metaphyseal dysplasia without hypotrichosis. A syndrome clinically distinct from
McKusick cartilage-hair hypoplasia. J Med Genet 1990;27:693-6.

2. Horn D, Rupprecht E, Kunze J, Spranger J. Anauxetic dysplasia, a spondylometaepiphyseal dysplasia with extreme dwarfism. J Med Genet 2001; 38:262-5.

3. Hermanns P, Tran A, Munivez E, Carter S, Zabel B, Lee B, et al. RMRP mutations in cartilage-hair hypoplasia. Am J Med Genet A 2006;140: 2121-30.

4. Reicherter K, Veeramani Al, Jagadeesh S. Cartilage-hair hypoplasia caused by novel compound heterozygous RMRP mutations. Indian Pediatr 2011; 48:559-61.

5. Bonafé L, Schmitt K, Eich G, Giedion A, Superti-Furga A. RMRP gene sequence analysis confirms a cartilage-hair hypoplasia variant with only skeletal manifestations and reveals a high density of single-nucleotide polymorphisms. Clin Genet 2002;61:146-51.

6. Vakkilainen S, Costantini A, Taskinen M, Wartiovaara-Kautto U, Mäkitie O. 'Metaphyseal dysplasia without hypotrichosis' can present with lateonset extraskeletal manifestations. J Med Genet 2020;57:18-22.

7. Nakashima E, Mabuchi A, Kashimada K, Onishi T, Zhang J, Ohashi H, et al. RMRP mutations in Japanese patients with cartilage-hair hypoplasia. Am J Med Genet A 2003;123A:253-6.

8. Bonafé L, Dermitzakis ET, Unger S, Greenberg CR, Campos-Xavier BA, Zankl A, et al. Evolutionary comparison provides evidence for pathogenicity of RMRP mutations. PLoS Genet 2005;1:e47.

9. Thiel CT and Rauch A. The molecular basis of the cartilage-hair hypoplasia-anauxetic dysplasia spectrum. Best Pract Res Clin Endocrinol Metab 2011:25:131-42.

10. Mäkitie $O$ and Vakkilainen S. Cartilage-hair hypoplasia - anauxetic dysplasia spectrum disorders. In: Adam MP, Ardinger HH, et al., eds. GeneReviews [Internet]. Seattle, WA: University of Washington, Seattle. 2012. 